\section{Fetomaternal Hemorrhage: A Case of Atypical Presentation with Favourable Outcome}

\author{
Ana Catarina Monteiro Lacerda*, Joana Margarida Cabrita \\ Extreia, Sofia Afonso Silva, Margarida Simão Rafael, Susana \\ Alexandra Madeira Correia and Ana Rute Ferreira
}

Pediatric Department, Centro Hospitalar Barreiro Montijo, Avenida Movimento das Forças Armadas, Barreiro, Portugal

\begin{abstract}
Fetomaternal Hemorrhage (FMH) occurs in 3:1000 live deliveries. The severity of the event depends on the rate and the size of the blood loss in relation to total fetal blood volume. Clinical findings range from pallor, respiratory distress, and hypovolemic shock to stillbirth or neonatal death. We report a clinical case of a newborn who suffered a severe fetomaternal transfusion, corroborated by the Kleihauer-Betke (KB) test, with favourable outcome.

Keywords: Fetal anemia; Fetomaternal hemorrhage; KleihauerBetke test
\end{abstract}

\section{Abbreviations}

FMH: Fetomaternal Hemorrhage;

KB: Kleihauer-Betke

\section{Introduction}

Fetomaternal hemorrhage was first described by Wiener in 1948 [1]. This condition is considered physiological if a small amount of fetal blood enters the maternal circulation [1] and it occurs in 50 to $75 \%$ of all pregnancies. In this case, the volume of the transfusion ranges from 1 to $50 \mathrm{~mL}$. The majority of blood losses are $1 \mathrm{~mL}$ or less, 1 in 400 cases are approximately $30 \mathrm{~mL}$ and 1 in 2000 the transfusion volume is about $100 \mathrm{~mL}$ [2].

Sometimes, besides the rarity of the condition, FMH involves a large amount of fetal blood which can lead to important fetal morbidity and mortality [1]. During pregnancy, clinical manifestations can be subtle and nonspecific which difficult the recognition of this condition. Antenatal suspicion of the diagnosis should occur when absent fetal movements is reported.

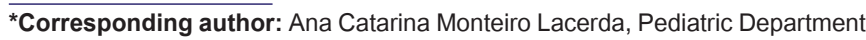
Centro Hospitalar Barreiro Montijo, Avenida Movimento das Forças Armadas Barreiro, Portugal, Tel: +351 910652534, E-mail: catarina_lacerda@hotmail.com

Citation: Lacerda ACM, Extreia JMC, Silva SA, Rafael MS, Correia SAM, et al. (2015) Fetomaternal Hemorrhage: A Case of Atypical Presentation with Favourable Outcome. J Neonatol Clin Pediatr 2: 007

Received: February 10, 2015; Accepted: March 04, 2015; Published: March 18, 2015
We describe this case to alert for this condition and the importance of maternal symptoms and newborn clinical findings. The prompt recognition and intervention is the key to the prognosis of this entity that can be fatal.

\section{Clinical Case Report}

A 31-year-old primiparous female, at 35 weeks gestational age, presented to obstetrics emergency department complaining of absence of fetal movements for the last $12 \mathrm{~h}$ before admission.

She had been regularly attending the antenatal consultations with no risk factors identified. Her prenatal laboratory results were unremarkable except for GBS-unknown. She had three normal obstetric ultrasounds (one of each trimester); her blood type was A+. Pregnancy was uneventful with no history of vomiting, blood loss or abdominal trauma.

On admission at the delivery unit, the obstetric ultrasound revealed no fetal movements with the presence of heart beat. The Cardiotocograph (CTG) was not tranquilizing as it showed prolonged deceleration and reduced variability with pathological trace that suggested a sinusoidal pattern and, as a result, an emergent caesarean section was performed (Figure 1).

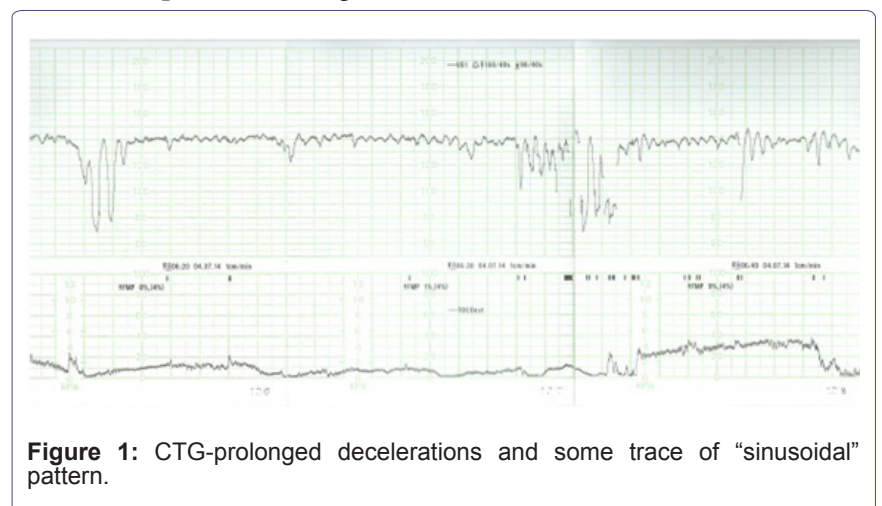

A baby boy was born weighing $2610 \mathrm{~g}$. The newborn had a circular of the umbilical cord around the arms. On examination at birth, he was markedly pale and hypotonic with respiratory depression. Orothracheal intubation and connection to mechanical ventilation was immediately performed. He responded well and was extubated 4 minutes after and transferred to the neonatal unit with oxygen directly to his face, for further evaluation and management. The Apgar score was $5 / 8 / 8$.

Initial blood gas from the umbilical cord revealed $\mathrm{pH} 7.27, \mathrm{pCO}_{2}$ $50.6 \mathrm{~mm} \mathrm{Hg}$, Hemoglobin 4.4, g/dL, bicarbonate $21.9 \mathrm{mmol} / \mathrm{L}$ and lactates $5.8 \mathrm{mmol} / \mathrm{L}$. Laboratory exams revealed $4.0 \mathrm{~g} / \mathrm{dL}$ of hemoglobin, white blood cell count of 47.700/10 EXP 9/L with $22.7 \%$ neutrophils (10.800), platelets count 183.000/10 EXP 9/L, DHL 680 UI/L, CK 190 UI/L. Further laboratory evaluation was unchanged (bilirubin, cardiac enzymes and $\mathrm{C}$ reactive protein). Coombs test and viral serology for Parvovirus B19 and Cytomegalovirus were negative. Hemoglobin electrophoresis showed a presence of $5 \%$ fetal hemoglobin on mother's blood. Kleihauer-Betke test was performed, since it is a more specific exam and quantifies the amount of blood 
transfusion. It revealed $17.8 \%$ of fetal red cells in maternal circulation, which corresponds to a volume of approximately $890 \mathrm{~mL}$ of fetal blood based on the formula: (\% of fetal cells determined by Kleihauer-Betke test/100) X $5000 \mathrm{~mL}=$ volume of FMH (in mL) [3] and also according to the fact that $1 \%$ of fetal erythrocytes in maternal circulation is equivalent to a fetal hemorrhage of $50 \mathrm{~mL}$ [4].

Two red blood cell transfusions were made and at 12 hours of life his hemoglobin was $13.3 \mathrm{~g} / \mathrm{dL}$, white blood cells count of 10.100/uL (Neutrophils: 64.4\%), platelets count of 219.000/uL and erythroblasts $87 / 100$ leucocytes.

The outcome was favorable with hemodynamic and respiratory stability and absence of abnormal movements. Cranial ultrasonography showed, in the $3^{\text {rd }}$ day of life, frontal bilateral parenchymal hyperechogenicity, was not present on $11^{\text {th }}$ day of life as the ultrasounds were made by two different physicians. The authors admit that the hyperechogenicity have not been valorized by the second physician.

Follow-up at 2 and 4 months revealed a normal physical and neurological examination.

\section{Discussion}

Clinical presentation of a FMH depends, on the one hand, on the volume of the transfusion and, on the other hand, on the velocity with which it had occurred [5]. The prognosis also depends on the prompt diagnosis and intervention.

FMH can occur as an acute or chronic event. In the chronic presentation, the hemorrhage has been prolonged or repeated during pregnancy, anemia developed slowly, giving the fetus the opportunity to develop hemodynamic compensation. In this case, the diagnosis is often postnatal and these infants may manifest only pallor at birth with no other complications [5].

In opposition, in acute $\mathrm{FMH}$, perinatal hypoxia and intrauterine death or severe anemia and hypoxia at birth can be present [5].

Neonatal anemia was the first manifestation of FMH in 35\% of the reported cases. In severe ones, shock and circulatory failure may be present [6].

In our clinical report, it's more likely to be a chronic transfusion given the rapid ability of the newborn to adapt to extra uterine life despite the hemoglobin value at birth. The absence of fetal movements noted by the mother was not due to the FMH but it was caused by the circular of the umbilical cord around the arms that made it impossible to the fetus to move.

Abdominal trauma and invasive techniques of prenatal diagnosis are related to FMH [1]. Physicians should consider alternative diagnosis to neonatal anemia such as isoimmune hemolytic anemia, congenital infections that result in bone marrow suppression (TORCH), sepsis, congenital erythrocyte defects and congenital hemoglobinopathies [6]. Clinical and laboratory evaluation of infection, Coombs test and viral serology should be performed.
In this case, the diagnosis of FMH was confirmed by the KB test. Pink fetal red blood cells are observed and counted in the mother's peripheral blood smear because fetal hemoglobin is resistant to acid elution, leaving discolored maternal cells (patients with sickle cell anemia or hereditary persistence of fetal hemoglobin may lead to a false positive result and $\mathrm{ABO}$ incompatibility may produce a false negative result) [2].

Although the $\mathrm{KB}$ test is inexpensive and requires no special equipment, it lacks standardization and is imprecise [3]. Flow cytometry, based on the use of anti-fetal hemoglobin for detection of fetal cells with fetal hemoglobin, represents an improvement of $\mathrm{KB}$ test since is more specific and precise [7].

Although the prognosis of massive FMH is poor, it can be improved if physicians early recognize this condition. When the infant is near-term gestation, immediate cesarean delivery is indicated. If, on the other hand, the fetus is still preterm, in uterus transfusion can be considered and has been shown to be effective and improves the prognosis [6].

Long term outcome for infants affected by massive FMH is unfavorable with death or neurological dysfunction [6]. The prognosis is more directly related to initial hemoglobin value and clinical manifestations post-delivery than with the transfused volume of blood [8].

The case reported emerged from a pregnancy with no risk factors. Mother's perception of decreased fetal movements, recognition of fetal distress on the CTG, immediate caesarean section and prompt hemodynamic and respiratory support to the newborn with early red blood cells transfusion contributed for this good outcome.

\section{References}

1. Barata S, Centeno M, Marques JP, Clode N, da Graça LM (2009) Hemorragia feto-materna grave Massive feto-maternal haemorrhage. Acta Obstet Ginecol Port 3: 169-172.

2. Kliegman RM (2011) Nelson Textbook of Pediatrics, (19thedn). Elsevier/ Saunders, USA.

3. Kim YA, Makar RS (2012) Detection of fetomaternal hemorrhage. Am J Hematol 87: 417-423.

4. Lobo AL, Tomás E, da Silva FP, Barbot J, Raposo T (2001) Anemia Neonatal Grave por Hemorragia Feto-Materna Caso Clínico. Acta Pediatr Port 32: 395-397.

5. Zuppa AA, Scorrano A, Cota F, D’Andrea V, Francciolla A, et al. (2008) Massive fetomaternal hemorrhage and late-onset neutropenia: description of two cases. Turk J Pediatr 50: 400-404.

6. Solomonia N, Playforth K, Reynolds EW (2012) Fetal-Maternal Hemorrhage: A Case and Literature Review. AJP Rep 2: 7-14.

7. Dziegiel MH, Nielsen LK, Berkowicz A (2006) Detecting fetomaternal hemorrhage by flow cytometry. Curr Opin Hematol 13: 490-495.

8. Kecskes Z (2003) Large fetomaternal hemorrhage: clinical presentation and outcome. J Matern Fetal Neonatal Med 13:128-132. 